\title{
Radial basis function and particle swarm optimization to predict range extender engine performance
}

\section{Bambang Wahono ${ }^{1 *}$, Achmad Praptijanto ${ }^{1}$, Widodo Budi Santoso ${ }^{1}$, Arifin Nur ${ }^{1}$, Suherman ${ }^{1}$ and Zong $\mathrm{Lu}^{2}$}

${ }^{1}$ Research Centre for Electrical Power and Mechatronics, Indonesian Institute of Sciences (LIPI), Komplek LIPI Jl Cisitu Gd. 20 Bandung, 40135, Phone: +62-222503055; Fax: +62-22-2504773

*Email: bambangwahono80@yahoo.co.id, bamb053@lipi.go.id

${ }^{2}$ Brother Industries, Ltd., Nagoya, Aichi, Japan

\begin{abstract}
Range extender engine is one of the potential technologies to develop in future. However, this technology still has performance and emission problem. To solve this problem, a new technology model and optimization method are needed. Therefore, for this purpose, the radial basis function and particle swarm optimization are used in the investigation. In this study, two types of radial basis function (RBF), Cauchy and Gaussian, were used to construct the prediction model of fuel consumption and range extender engine emission. Both RBF types were compared with one another to decide on which one is the best to predict the model. By using data from a two-cylinder $999 \mathrm{cc}$ gasoline engine, generator, battery, electric motor and other vehicle components, a range extender electric vehicle (REEV) model simulation was built. Based on this simulation result, some output data will be taken as training set data to build the prediction model of fuel consumption and emission and some output data will be taken to test this prediction model in MATLAB. Moreover, particle swarm optimization (PSO) was used to calculate some control parameters of range extender engine to optimize fuel consumption and emission based on the best model. The result shows that the radial basis function is successfully used to develop the prediction model of some range extender engine control parameters. The Cauchy type radial basis function has better accuracy than Gaussian type radial basis function. Moreover, based on the model, PSO method is able to calculate control parameters efficiently to optimize evaluation item based on the model.
\end{abstract}

Keywords: range extender engine; radial basis function; particle swarm optimisation.

\section{INTRODUCTION}

In the last decade, a big problem in transportation sector is the significant portion of fossil fuels consumption and major contributor to air pollutions [1-4]. One of the big sources of air pollution is the significant increase of conventional vehicle numbers in recent years [5]. Based on these conditions, a new vehicle technology to reduce air pollution and fuel consumption is required. Many researchers and vehicle companies have developed some new vehicle technologies to decrease fuel consumption and air pollution, such as the electric vehicle [6-10] and hybrid electric vehicle [11-13]. However, Range Extended Electric Vehicle (REEV) [14-18] is the most suitable vehicle technology for the future as 
compared to electric vehicle and hybrid electric vehicle $[19,20]$. The main components of REEV are electric motor, battery and range extender, which is a small generator set that consists of a generator and a small engine in series configuration [21-23]. This range extender engine works if the state of charge (SOC) of battery decreases until a certain condition. Therefore, SOC is the important parameter that influences the range extender engine performance. In this step, range extender engine provides electricity for the vehicle by recharging the battery or driving the electric motor directly during driving so as to continue the vehicle operation. Since this vehicle model still uses the engine as a driver, it requires fuel, and of course produces emissions. Due to environmental concern, range extender engine exhaust emissions have to meet the increasingly stringent exhaust emission limitations. Besides, fuel efficiency standards boost the development of range extender engine control technologies. The fundamental point of control system for range extender engine is the control energy strategies which significantly affect vehicle performance, especially fuel consumption and exhaust gas emission. Thus, researchers have done many research to develop the control energy strategy of engine, especially in hybrid electric vehicle [24-30]. However, research to develop the control energy strategy, especially for range extender engine, is very limited. Considering the importance of reducing fuel consumption and exhaust gas emissions, the control of a large number of control parameters of the range extender engine is crucial. SOC of battery is the important parameter that affects a range extender engine performance because the range extender engine operation is initiated if the battery SOC drops below a specified level. Although SOC of battery is the control parameter used to turn on the range extender engine, its performance cannot be optimally improved. Therefore, a method to improve its performance is required.

This paper presents the construction of a prediction model for range extender engine performance, such as fuel consumption and exhaust gas emission, and an optimization method for the prediction model to control the number of control parameters appropriately in accordance with fuel consumption and exhaust gas emission as its output objectives. The radial basis function (RBF) was applied to construct the range extender engine model. It describes the multiple control parameters in relation to the characteristic values of range extender engine performance, such as fuel consumption and exhaust emission. This was demonstrated in modelling non-linear systems. RBF type Cauchy and Gaussian were used to build the prediction model and compared to one another. To improve the range extender engine performance, particle swarm optimization (PSO) was applied in the model. PSO was applied to calculate the optimal control parameters and optimize evaluation item based on the model.

\section{METHODS AND MATERIALS}

\section{Model Construction}

Prediction model describes the relationships between several predictor variables $x_{i}(i=1 \ldots . . n, n>1)$ and one or more response variables $y$.

$$
y=f\left(x_{1}, x_{2}, \cdots, x_{n}\right)+\varepsilon
$$

where $\varepsilon$ is error.

\section{Radial Basis Function}

Radial basis function (RBF) is a multi-variate interpolation function method proposed by Powell[31]. RBF consists of a unit with the nonlinear activation function, which makes 
the distance between input and prototype a variable. It is often used for building the approximation of functions in the following form:

$$
y(x)=\sum_{i=1}^{N} w_{i} \phi\left(\left\|x-c_{i}\right\|\right)
$$

where the approximating function $y(x)$ is represented as a sum of $N$ radial basis functions, each associated with a different centre $\boldsymbol{c}_{i}$, and weighted by an appropriate coefficient $w_{i}$. The weights $w_{i}$ can be estimated by using the matrix methods of linear least squares, because the approximating function is linear in the weights. There are two kinds of RBF selection method, i.e. forward selection method and backward selection method. The forward selection is as follows: starting with an empty subset, to which is added one basis function at a time, one which reduces the most sum squared error, until it reaches a chosen criterion and finally stops decreasing. Backward selection method is as follows: starting with the full subset, from which it is removed by one basis function at a time, the one which increases the least sum squared error, until once again the chosen criterion stops decreasing. In this study, forward selection method was chosen to identify the model.

\section{Prediction Model of RBF}

In this study, the following form was used to build the model.

$$
f(x)=\sum_{j=1}^{m} w_{j} h_{j}(x)
$$

The model $f$ is expressed as a linear combination of a set of $m$ fixed functions. It is often called basis functions by analogy with the concept of a vector being composed of a linear combination of basis vectors. The choice of the letter $w$ is for the coefficients of the linear combinations and the letter $h$ is for the basis functions which have weights and hidden units. $m$ is the number of the hidden unit communication function. The architecture of $\mathrm{RBF}$ is shown in Figure 1.

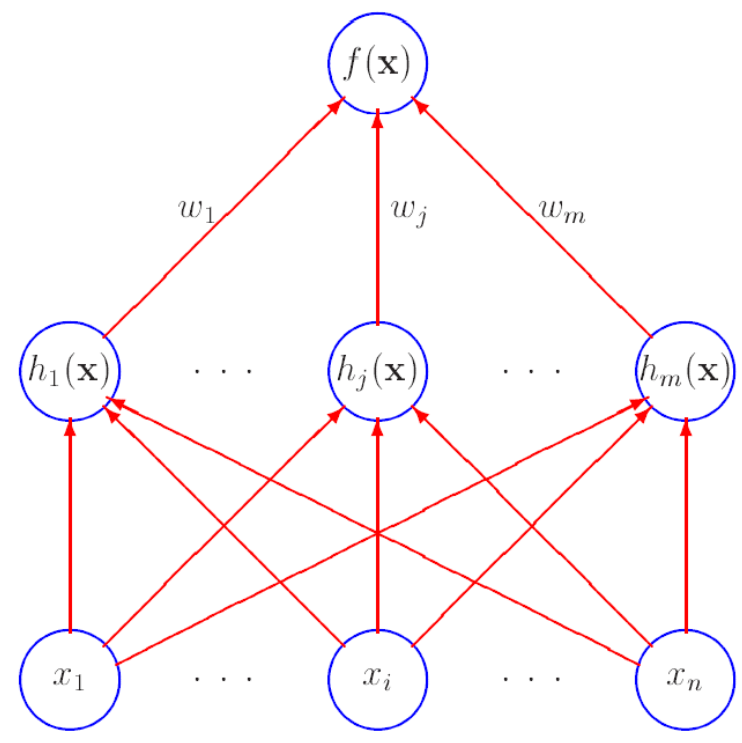

Figure 1. The Architecture of radial basis function.

The model performs bias correction and revised the bias later.

$$
f(x)=b+\sum_{j=1}^{m} w_{j} h_{j}(x)
$$


where, $b$ is the bias value. Hidden units transfer function, $h_{j}$ is

$$
h_{j}(x)=\phi\left(z_{j}(x)\right)
$$

where $z$ is the distance.

In this study, the RBF uses two types of function, the Cauchy and Gaussian functions, as indicated in Table 1.

Table 1. Two types of RBF.

\begin{tabular}{ccc}
\hline Type & String & $\theta$ \\
\hline Gaussian & 'g' & $e^{-z}$ \\
Cauchy & 'c' & $\frac{1}{(1+z)}$ \\
\hline
\end{tabular}

The transfer function of the hidden unit is radiating, and each hidden unit is related to a vector of the centre and the scale. The distance is

$$
z_{j}(x)=\sqrt{\sum_{k=1}^{n} \frac{\left(x_{k}-c_{j k}\right)^{2}}{r_{j k}^{2}}}
$$

where $c_{j k}$ is the centre and $r_{j k}$ is radius.

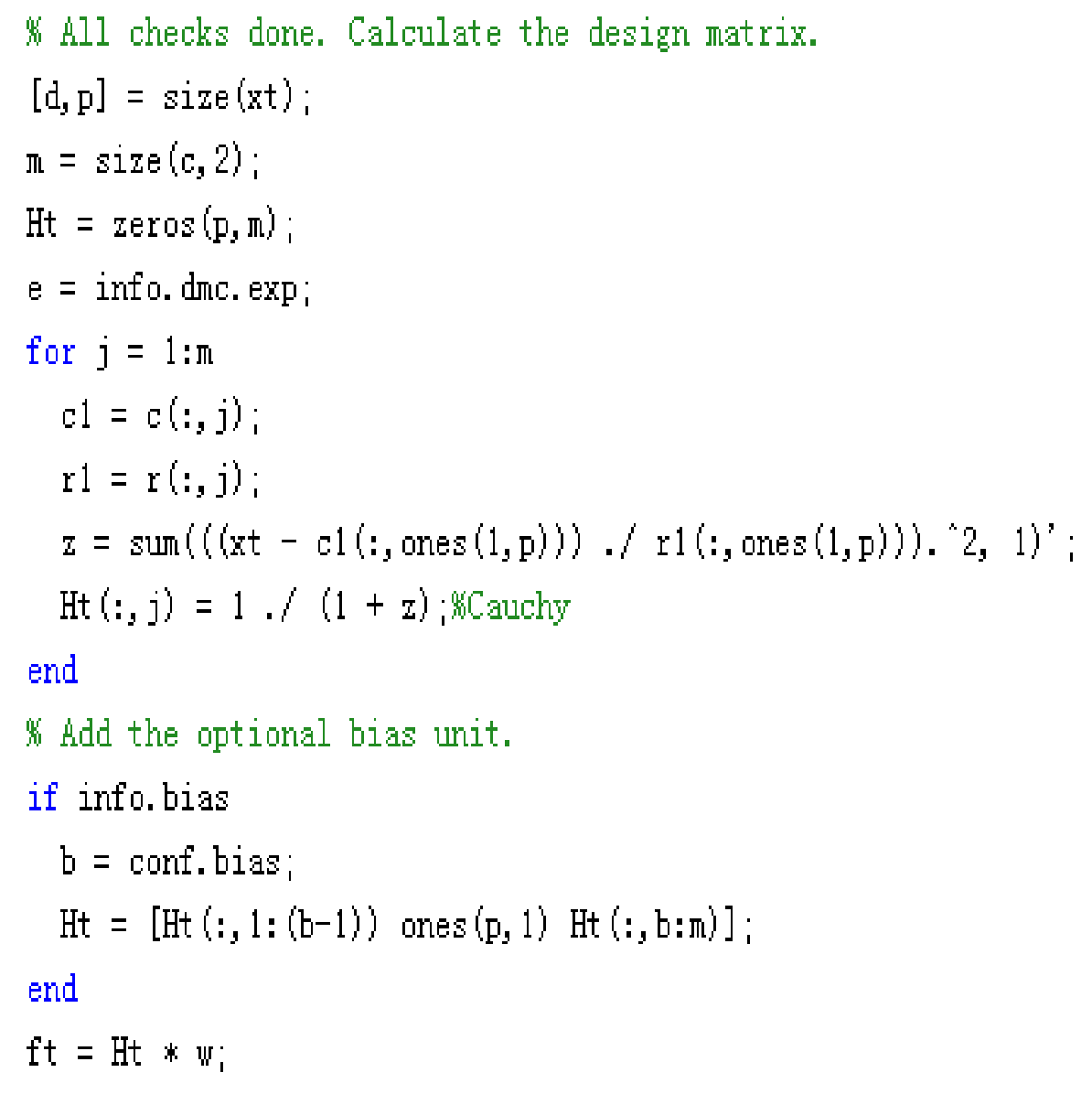

Figure 2. Code of RBF model. 
When the system is made $y_{i}=f_{i}(x)$, it depends on the least squares method.

$$
\begin{aligned}
& h_{1}\left(x_{1}\right) w_{1}+h_{2}\left(x_{1}\right) w_{2}+\ldots+h_{m}\left(x_{1}\right) w_{m}=y_{1} \\
& h_{1}\left(x_{2}\right) w_{1}+h_{2}\left(x_{2}\right) w_{2}+\ldots+h_{m}\left(x_{2}\right) w_{m}=y_{2} \\
& \ldots . . . \ldots \ldots \\
& h_{1}\left(x_{p}\right) w_{1}+h_{2}\left(x_{p}\right) w_{2}+\ldots+h_{m}\left(x_{p}\right) w_{m}=y_{p}
\end{aligned}
$$

In other side $w$ is

$$
w=\left(H^{T} H\right)^{-1} H^{T} y
$$

where $H$ is the design matrix.

The code of the RBF prediction model which was built in Matlab is shown in Figure 2. In this study, the correlation coefficient $(R)$ was used to evaluate the prediction accuracy of $\mathrm{RBF}$ where $R \leq 1$ when the prediction is perfect, $R=1$. The purpose of calculating $R$ is to determine the existing relationship between the actual and the prediction values by the model.

\section{Particle Swarm Optimization Algorithm}

The algorithm particle swarm optimization (PSO) was introduced by Eberhart and Kennedy $[32,33]$. PSO algorithm is a technique-based stochastic optimization inspired by the social behaviour of a flock of birds or a school of fish. PSO algorithm is used to simulate a flock of birds social behaviour with the following analogy; random group of birds looking for food in an area. In these areas, there is only a piece of food to search. The whole bird does not know the location of foods. But they know these foods are within each iteration. So what is the best strategy to find the foods? One of the most effective ways is to follow the birds closer to the food. PSO algorithm is one of the optimization algorithms that can be used for decision making. But it can also be used to search the path. In this study, PSO Algorithm was used to search the position by the return value of minimal function. PSO is a technique of optimization by calculating continuously candidate solutions by using a reference of quality. These algorithms optimize the problems by moving particles (potential solutions) in the space problems by using certain functions for the position and velocity of a particle. The movement of particles is influenced by the best solution of the particle and the best solution from. A collection of these particles is called the swarm, and eventually this swarm will move towards the best solution.

The process of PSO algorithm is as follows: First, initialise a set of random particles (each particle represents a possible solution to an optimization problem). Second, initialise the position of each particle $\left(X_{i}\right)$ and velocity of every particle $\left(V_{i}\right)$. Third, calculate the value fluctuation of each particle $F_{i}$ based formulas and models that were determined in accordance with the optimization problem. Fourth, for each particle, compare with the value fluctuation $F_{i}$ that has achieved the best value $P_{i d}$ (local best), if $F_{i}<P_{i d}$, then $P_{i d}$ replaced with $F_{i}$. Fifth, for each particle, compare the fluctuation value $F_{i}$ with the best value achieved in the population $P_{g d}$ (global best), if $F_{i}<P_{g d}, P_{g d}$ then replaced with $F_{i}$. Sixth, based on the similarities of step 4 and 5, the speed $\left(V_{i}\right)$ and the position of the particle $\left(X_{i}\right)$ are changed. The formula of velocity change is:

$$
V_{i d}^{k+1}=v_{i d}^{k}+c_{1} r_{1}\left(P_{i d}^{k}-X_{k}^{i}\right)+c_{2} r_{2}\left(P_{g d}^{k}-X_{i d}^{k}\right)
$$


where $c_{1}$ is a learning factor for particle and $c_{2}$ is learning factor for the swarm and usually of equal values of 2 . Although in fact, $c_{1}$ and $c_{2}$ are between the range $(0,4)$ and $\mathbf{r}_{1}$ and $\mathbf{r}_{2}$ are uniformly distributed random numbers in the range 0 and $1 . w$ is the inertia weight. In the PSO algorithm, the balance between global and local exploration capabilities is primarily controlled by the inertia weight and a decrease in the speed parameter to avoid stagnation in the local optimum particle. The formula of position change is:

$$
X_{i d}^{k+1}=X_{i d}^{k}+V_{i d}^{k+1}
$$

Finally, if the final conditions are met (the maximum iteration value or the optimum value is reached) then the iteration stops and an optimum value is obtained, but if it is not reached, then step 3 is repeated.

\section{Powertrain Configuration of Range Extended Electric Vehicle}

The schematic of Range Extended Electric Vehicle (REEV) powertrain configuration is shown in Figure 3. In this vehicle model, series configuration is used as the main system. The main components of this vehicle are range extender (engine and generator), battery and electric motor. In this model, the electric motor functions to transform electrical energy from battery to mechanical works. On the other side, the engine, which is coupled with generator, has function to generate electrical energy to recharge the battery. REEV works in two modes under rule-based control; electric vehicle (EV) mode and range extender (RE) mode. EV mode is operated when the distance is short and all propulsion power is supplied by the battery. Range extender mode is activated when the distance is long. This condition will happen if the SOC of battery drops below a certain level until a desired SOC is achieved and it will be off as long as there is sufficient energy from battery for pure electric driving.

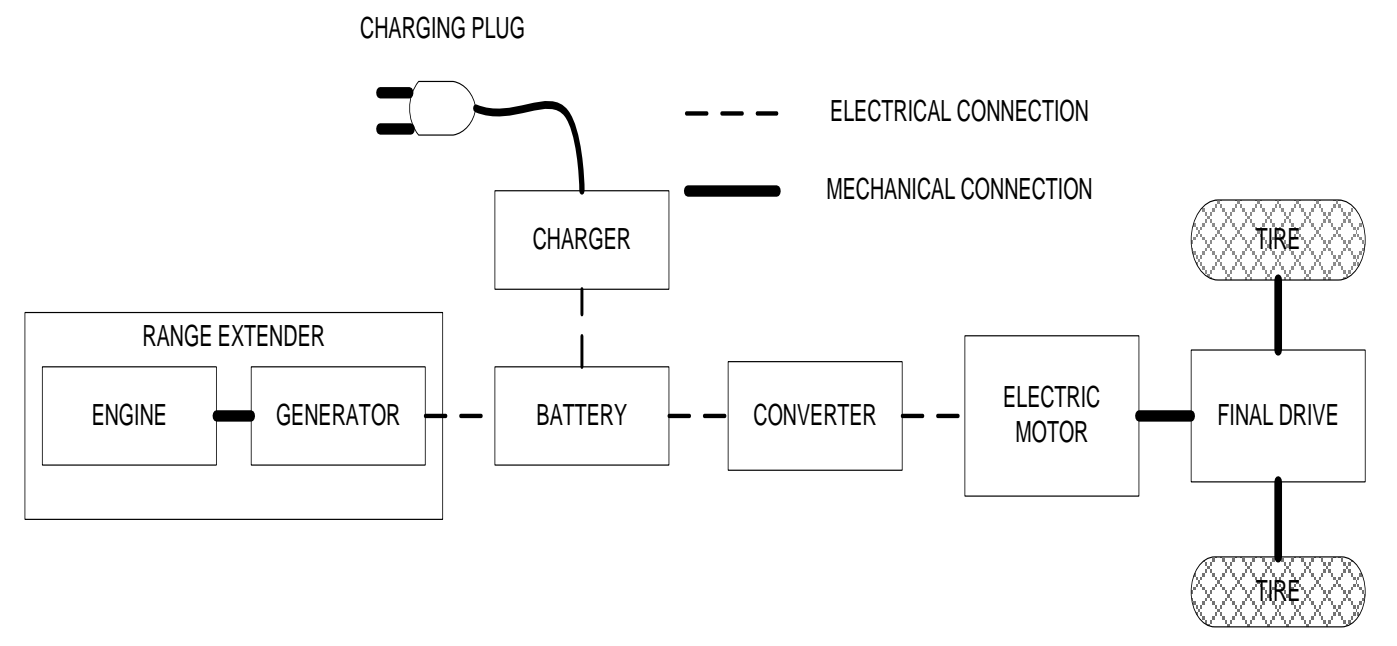

Figure 3. REEV powertrain configuration.

Two cylinder $999 \mathrm{cc}$ gasoline engines were used as a sub-system of REEV. The maximum power of engine was $42.6 \mathrm{~kW}$ and the maximum torque was $104.5 \mathrm{Nm}$. The generator model platform was AF 130 synchronous-axial flux with nominal output power of $64 \mathrm{~kW}$, maximum speed of $8000 \mathrm{rpm}$ and weight of $30.5 \mathrm{~kg}$ [34]. The battery model deployed was 30 units lithium-ion LiFeYPO4, with $200 \mathrm{Ah} / 3.2 \mathrm{~V}$ [35]. The electric motor model was HPEVS AC-20 96V, AC induction motor [36]. They were simulated under AVL Cruise vehicle simulator. The basic parameters of REEV are shown in Table 2. 
Table 2. Basic parameter of REEV.

\begin{tabular}{ll}
\hline Parameter & REEV \\
\hline Curb Weight & $1200[\mathrm{~kg}]$ \\
Gross Weight & $1580[\mathrm{~kg}]$ \\
Frontal Area & $1.97\left[\mathrm{~m}^{2}\right]$ \\
Dynamic Rolling Radius & $301[\mathrm{~mm}]$ \\
Final Drive Transmission Ratio & 4.266 \\
\hline
\end{tabular}

Table 3. Control parameters

\begin{tabular}{lll}
\hline $\begin{array}{l}\text { Control } \\
\text { Parameter }\end{array}$ & Meaning & Variation \\
\hline $\mathrm{x}_{1}$ & SOC $\min [\%]$ & $35,40,45$ \\
$\mathrm{x}_{2}$ & SOC $\max [\%]$ & $45 ; 50 ; 55 ; 60 ; 65 ; 70 ; 75$ \\
$\mathrm{x}_{3}$ & Speed $[\mathrm{rpm}]$ & $3000 ; 3100 ; 3200 ; 3300 ; 3400 ; 3500 ; 3600 ; 3700 ;$ \\
& & $3800 ; 3900 ; 4000 ; 4100 ; 4200 ; 4300 ; 4400 ; 4500$ \\
\hline
\end{tabular}

Table 4. Optimization Objective.

\begin{tabular}{ll}
\hline Optimization Objective & Range extender engine \\
\hline $\mathrm{y}_{1}$ & Fuel consumption $[1 / 100 \mathrm{~km}]$ \\
$\mathrm{y}_{2}$ & NOx $[\mathrm{g}]$ \\
$\mathrm{y}_{3}$ & $\mathrm{CO}[\mathrm{g}]$ \\
$\mathrm{y}_{4}$ & $\mathrm{HC}[\mathrm{g}]$ \\
\hline
\end{tabular}

Table 5. Example data from AVL Cruise simulation.

\begin{tabular}{llllllll}
\hline No & $\begin{array}{c}\text { SOC } \\
\text { Min } \\
(\%)\end{array}$ & $\begin{array}{c}\text { SOC } \\
\text { Max } \\
(\%)\end{array}$ & $\begin{array}{c}\text { Engine } \\
\text { Speed } \\
(\mathrm{rpm})\end{array}$ & $\begin{array}{c}\text { Fuel } \\
\text { Consumption } \\
(1 / 100 \mathrm{~km})\end{array}$ & $\begin{array}{c}\text { NOx } \\
(\mathrm{g})\end{array}$ & $\begin{array}{c}\mathrm{CO} \\
(\mathrm{g})\end{array}$ & $\begin{array}{c}\mathrm{HC} \\
(\mathrm{g})\end{array}$ \\
\hline 1 & 35 & 50 & 3000 & 1.4 & 34.18 & 554.65 & 5.81 \\
2 & 35 & 50 & 3200 & 1.52 & 36.28 & 592.88 & 6.32 \\
3 & 35 & 50 & 3500 & 1.69 & 39.52 & 651.34 & 7.1 \\
4 & 35 & 50 & 4000 & 1.97 & 45.12 & 749.56 & 8.37 \\
5 & 40 & 50 & 3000 & 1.88 & 45.88 & 744.19 & 7.79 \\
6 & 40 & 50 & 3200 & 1.74 & 41.63 & 680.1 & 7.24 \\
7 & 40 & 50 & 3500 & 1.6 & 37.63 & 620.14 & 6.75 \\
8 & 40 & 50 & 4000 & 1.58 & 36.15 & 600.27 & 6.7 \\
9 & 40 & 50 & 4500 & 1.65 & 37.63 & 623.98 & 7.01 \\
10 & 45 & 50 & 2000 & 1.35 & 39.03 & 586.13 & 5.09 \\
11 & 45 & 50 & 2500 & 1.8 & 46.76 & 736.36 & 7.17 \\
12 & 45 & 50 & 3000 & 1.86 & 45.27 & 734.12 & 7.68 \\
13 & 45 & 50 & 3200 & 1.74 & 41.77 & 682.38 & 7.26 \\
14 & 45 & 50 & 3500 & 1.96 & 46.04 & 758.36 & 8.25 \\
15 & 45 & 50 & 4000 & 1.94 & 44.5 & 739.06 & 8.25 \\
\hline
\end{tabular}


To optimize the fuel consumption and exhaust gas emission of REEV, AVL Cruise has built the REEV model. In this study, the control parameters are set in Table 3 and the optimization objectives are listed in Table 4. Based on this simulation result, some output data will be taken as training set data to build the prediction model and some output data will be taken to test the prediction model in MATLAB. In this study, the number of set data used to create the model was 250 data and number of set data used to test the model was 44 data. A simulation was realised by using MATLAB, and performed on a PC with an Intel(R) Pentium(R) Dual CPU T2390 @ 1.86 GHz, and 0.99 GB RAM. The example data that produced from AVL Cruise software simulation is shown in Table 5.

\section{RESULTS AND DISCUSSION}

\section{Prediction and Actual Result of the Prediction Model}

Radial functions are a special class of functions. Their characteristic feature is that their response decreases or increases monotonically with distance from a central point. The centre, the distance scale, and the precise shape of the radial function are parameters of the model, all fixed if it is linear.

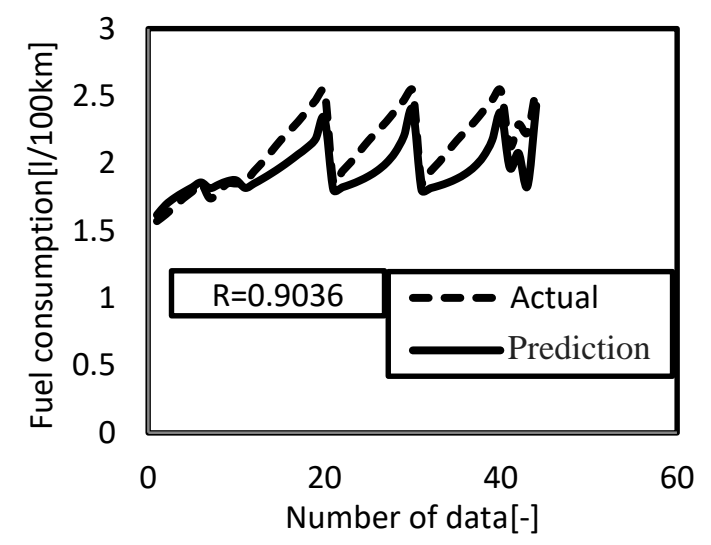

(a)

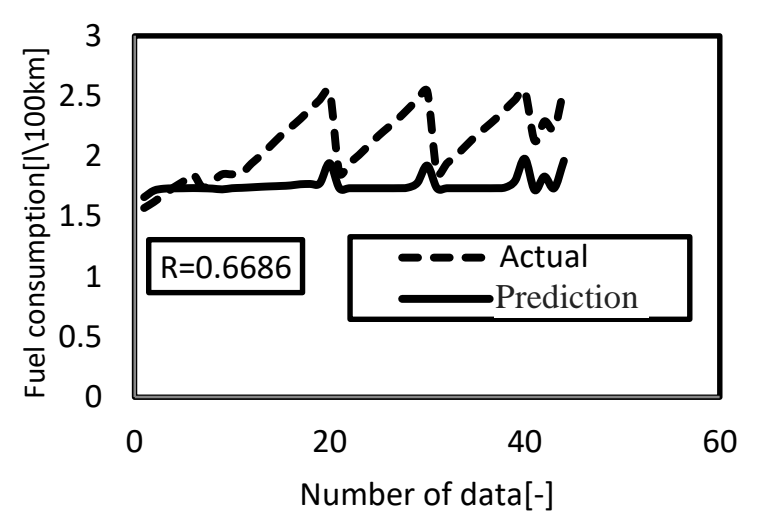

(b)

Figure 4. Prediction and actual result of the fuel consumption rate (a) by RBF Cauchy; (b) by RBF Gaussian.

Based on the radial basis function method, the prediction and actual value of the prediction model is as follows. The prediction and actual values of fuel consumption by radial basis function are shown in Figure 4. The solid line is prediction value and dotted line is actual value. Figure 4(a) shows the comparison of fuel consumption in prediction and actual values by RBF Cauchy. The correlation coefficient $R$ of this model was 0.9036 . If compared with Figure 4(b), fuel consumption by RBF Gaussian, the correlation coefficient $R$ was only 0.6686 . The model of fuel consumption built by RBF Cauchy was more accurate than RBF Gaussian. In the same case, the models of NOx, CO and HC emissions built by RBF Cauchy and RBF Gaussian were obtained. The models are shown in Figure 5(a-f). Figure 5(a-b) shows that the predictive model of NOx emission by RBF Cauchy had higher accuracy than the predictive model of NOx emission by RBF Gaussian. This is proven by the correlation coefficient 0.8627 for NOx emission with RBF Cauchy and 0.6293 for NOx emission with RBF Gaussian. It can be regarded that the RBF Cauchy can effectively estimate the objectives better than RBF Gaussian for NOx emission. Based on the prediction model of NOx emission by RBF Cauchy and RBF 
Gaussian in Figure 5(a-b), it can also be explained that the RBF Gaussian monotonically increase with the distance from the centre but was too small. Thus, if compared with the actual value, the prediction value had high discrepancy around $25 \%$.

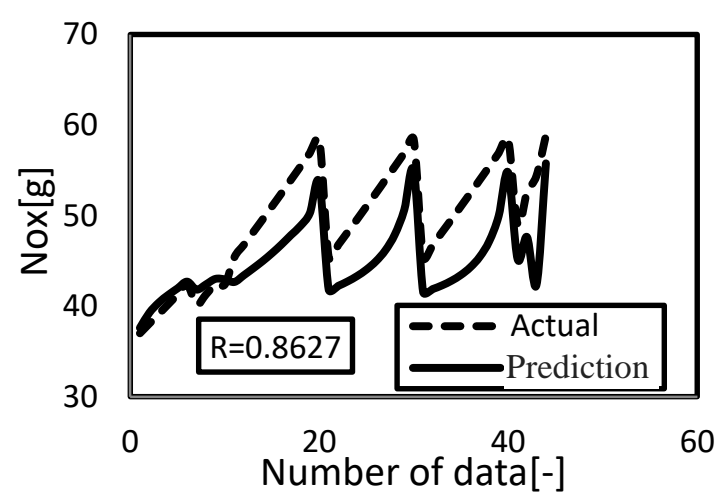

(a)

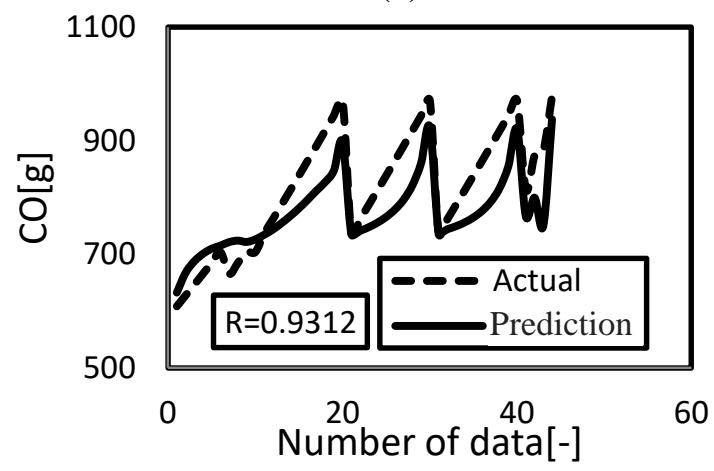

(c)

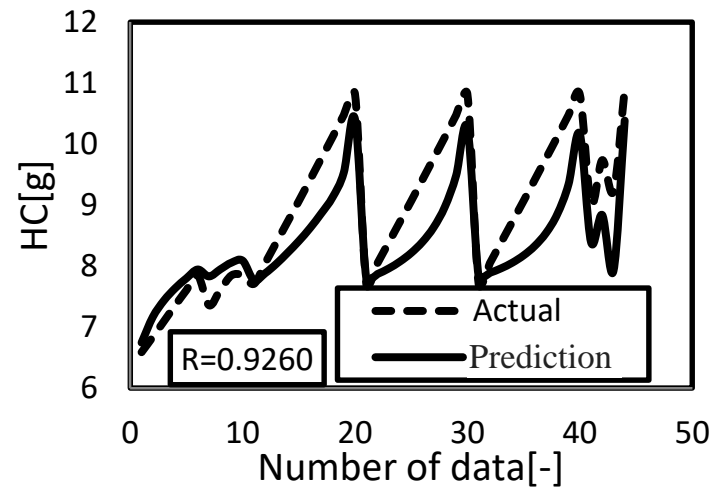

(e)

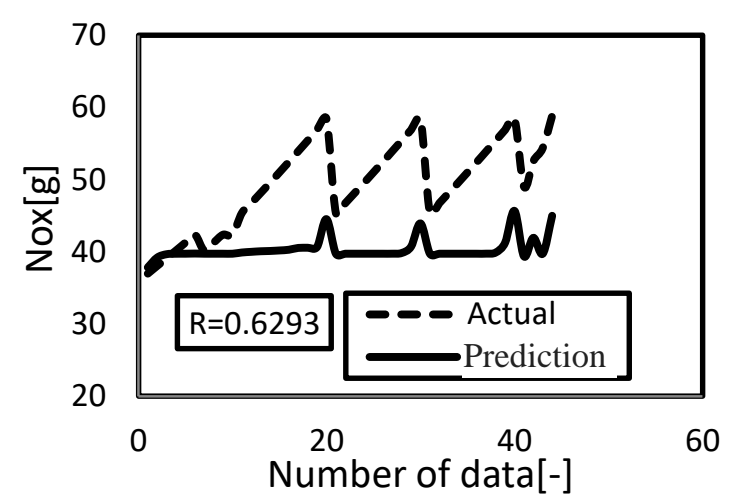

(b)

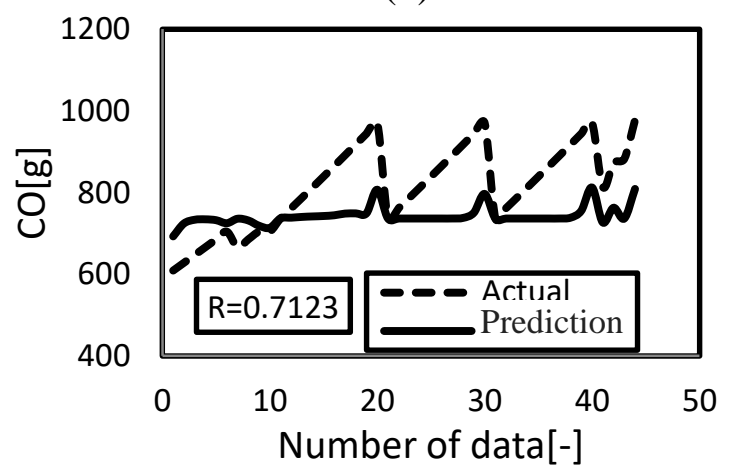

(d)

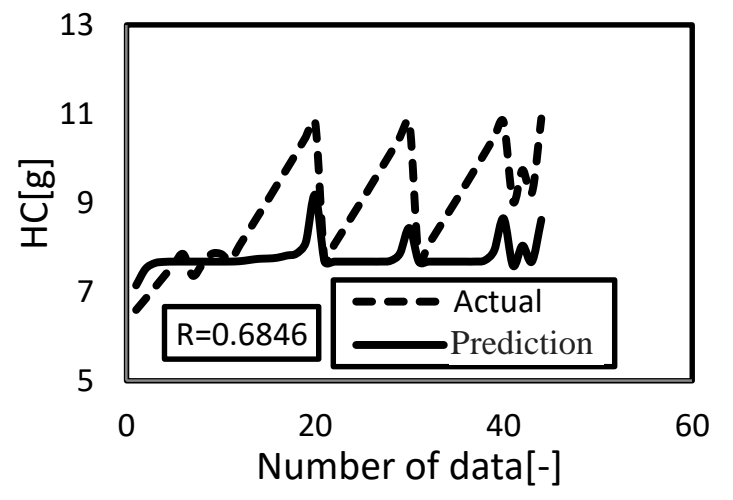

(f)

Figure 5. Prediction and actual result of (a) the NOx emission by RBF Cauchy; (b) the

NOx emission by RBF Gaussian; (c) the CO emission by RBF Cauchy; (d) the CO emission by RBF Gaussian; (e) the HC emission by RBF Cauchy; (f) the HC emission by RBF Gaussian.

In contrast, RBF Cauchy which, in the case of scalar input, is monotonically increased with the distance from the centre and the discrepancy is only $8.33 \%$. The same thing happened to the $\mathrm{CO}$ and $\mathrm{HC}$ emission. It is shown in Figure 5(c-f). Moreover, RBF Cauchy is capable to monotonically increase with the distance from the centre with only 9.09\% discrepancy for $\mathrm{CO}$ emission and $4.54 \%$ for $\mathrm{HC}$ emission, it has high correlation coefficient $(R)$ of 0.9312 for $\mathrm{CO}$ emission and 0.9260 for $\mathrm{HC}$ emission. In contrast, the RBF Gaussian had high discrepancy, i.e., $20 \%$ for $\mathrm{CO}$ emission and $18.18 \%$ for $\mathrm{HC}$ 
emission and low correlation coefficient $(R)$ of 0.7123 for $\mathrm{CO}$ emission and 0.6845 for $\mathrm{HC}$ emission. Based on this explanation, it can be regarded that the RBF Cauchy can effectively estimate the objectives better than RBF Gaussian for $\mathrm{CO}$ and $\mathrm{HC}$ emission too. In order to improve the fuel consumption and emissions of range extender engine, in the next step, PSO was used to find the optimal range extender engine control parameters based on the RBF Cauchy model efficiently.

\section{Optimization of Range Extender Engine Control Parameter}

The simulation by using PSO method was carried out based on some conditions, i.e., number of particle was 30 and maximum number of iteration was 150 . The important factor to get the optimal value of range extender engine control parameter in PSO method is the fitness function. In this study, one optimization objective was adjusted to a fitness function as:

$$
\operatorname{Min}_{j}=0.2 Y_{1}+0.4 Y_{2}+0.25 Y_{3}+0.15 Y_{4}
$$

where $Y$ is the normalised values of the $y$ (Equation (1)). $y_{1}, y_{2}, y_{3}$ and $y_{4}$ are the optimization objectives of range extender engine.

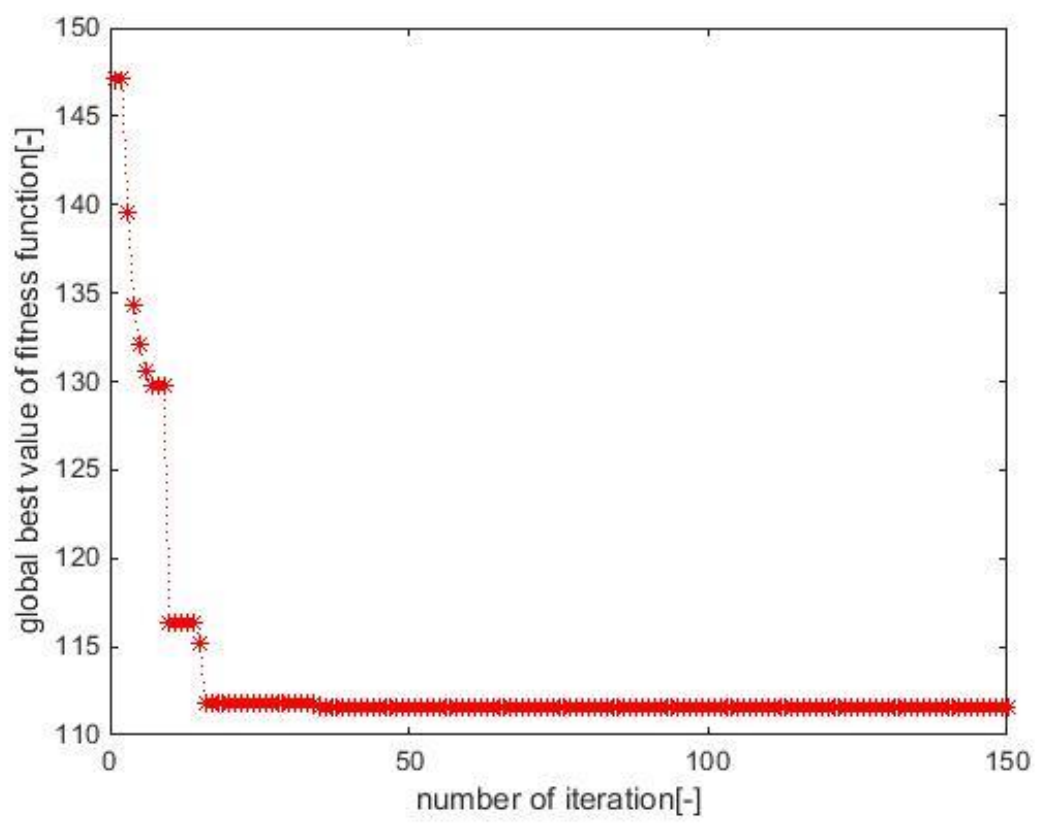

Figure 8. Convergence of PSO $(\mathrm{J}=111.5487)$.

Based on the simulation result with PSO method, the optimal value of range extender engine control parameters was found. The optimal values of range extender engine control parameters are listed in Table 6. The computing time took 22.036061 seconds. Convergence of the global best fitness value is shown in Figure 8. The global best fitness value convergences at $J=111.5487$. Based on the optimal range value of extender engine control parameter, the optimization objectives of range extender engine can be predicted. Based on this result, it can be explained that the optimal value to get the optimal value of fuel consumption and emission of NOx, CO and $\mathrm{HC}$ are SOC min $35 \%$, SOC max $48 \%$ and engine speed $3058 \mathrm{rpm}$. If the control parameter had used other variations, then the value of fuel consumption and emission $\mathrm{NOx}, \mathrm{CO}$ and $\mathrm{HC}$ are not optimal. It means, sometimes the value of fuel consumption is low but the emission value 
is too high. Otherwise, the value of emission is low but the value of fuel consumption is high. Table 7 shows comparison of the prediction and actual optimal values of range extender engine of optimization objectives based on prediction model from Table 6 .

Table 6. The optimal value of range extender engine control parameters.

\begin{tabular}{lll}
\hline $\begin{array}{l}\text { Control } \\
\text { Parameter }\end{array}$ & Meaning & Variation \\
\hline $\mathrm{x}_{1}$ & SOC $\min (\%)$ & 35 \\
$\mathrm{x}_{2}$ & SOC $\max (\%)$ & 48 \\
$\mathrm{x}_{3}$ & Speed (rpm) & 3058 \\
\hline
\end{tabular}

Table 7. Comparison of actual and prediction range extender engine optimization objectives.

\begin{tabular}{lllll}
\hline Comparison & Fuel consumption $[1 / 100 \mathrm{~km}]$ & NOx $[\mathrm{g}]$ & $\mathrm{CO}[\mathrm{g}]$ & $\mathrm{HC}[\mathrm{g}]$ \\
\hline Actual & 1.38 & 33.49 & 544.98 & 5.75 \\
Prediction & 1.35 & 32.54 & 532.05 & 5.62 \\
\hline
\end{tabular}

The range extender engine optimal control parameters in Table 6 were validated in the AVL Cruise and the results of validation based on the simulated optimal control parameters were compared with the calculated range extender engine optimal objective values. The actual result as the validation result and the prediction result as the calculation result are shown in Table 7. Based on Table 7, the actual and prediction result have the value of discrepancy in all range extender engine optimization is very small. The discrepancy of the fuel consumption is $2.17 \%, \mathrm{NOx}$ is $2.84 \%, \mathrm{CO}$ is $2.37 \%$ and $\mathrm{HC}$ was $2.26 \%$. It can be observed that the prediction values of fuel consumption, NOx, HC of range extender engine is in agreement with the actual values from AVL Cruise. Based on this result, the PSO method is to be the effective method in this optimization problem.

\section{CONCLUSIONS}

Based on the results and discussion, it can be reported that the predicting model of fuel consumption (NOx, CO) and HC emissions of range extender engine by using RBF were done. This study shows that the predictive accuracy by RBF Cauchy method was higher than RBF Gaussian. This is proven by the value correlation coefficient of RBF Cauchy that is higher than RBF Gaussian of around 0.9000 or more. In order to improve fuel efficiency and exhaust emissions of range extender engine, PSO was used to find the optimal value of range extender engine. Based on the optimal value of range extender engine control parameter, the optimization objectives of range extender engine can be estimated and as compared to the actual values of optimization objective of range extender engine. The result proved that the PSO was an effective method for engine optimization problem. In order to improve the performance of REEV especially in fuel consumption and emission, in future work, these control parameters and optimization objective should be more and must be validated on the road, and the results of validation based on the optimal control parameters simulation should be compared with the calculated optimal objective values. Then, the prediction model which added PSO should be mounted as a controller, and the control performance should be evaluated. 


\section{ACKNOWLEDGEMENTS}

The authors are obliged to Indonesian Institute of Sciences for providing laboratory facilities and financial assistance under Competitive Research Grant with project number 934/F/2014.

\section{REFERENCES}

[1] Kamil M, Rahman MM, Bakar RA. Integrated simulation model for composition and properties of gases in hydrogen fueled engine. International Journal of Automotive and Mechanical Engineering. 2013;8:1242-55.

[2] Kamil M, Rahman MM, Bakar RA. An integrated model for predicting engine friction losses in internal combustion engines. International Journal of Automotive and Mechanical Engineering. 2014;9:1695-708.

[3] Nayak C, Pattanaik BP, Nayak SK. Effect of preheated jatropha oil and jatropha oil methyl ester with producer gas on diesel engine performance. International Journal of Automotive and Mechanical Engineering. 2014;9:1709-22.

[4] Vashist D, Ahmad M. Statistical analysis of diesel engine performance for castor and jatropha biodiesel-blended fuel. International Journal of Automotive and Mechanical Engineering. 2014;10:2155-69.

[5] Ji S, Cherry CR, Matthew JB, Wu Y, Marshall JD. Electric vehicles in China: emissions and health impacts. Environmental Science \& Technology. 2012;46:2018-24.

[6] Salleh I, Zain MZM, Hamzah RR. Evaluation of annoyance and suitability of a back-up warning sound for electric vehicles. International Journal of Automotive and Mechanical Engineering. 2013;8:1267-77.

[7] Rahmat MS, Ahmad F, Yamin AKM, Aparow VR, Tamaldin N. Modelling and torque tracking control of permanent magnet synchronous motor for hybrid electric vehicles. International Journal of Automotive and Mechanical Engineering. 2013;7:955-67.

[8] Hawkins TR, Singh B, Majeau-Bettez G, Strømman AH. Comparative environmental life cycle assessment of conventional and electric vehicles. Journal of Industrial Ecology. 2013;17:53-64.

[9] Seixas J, Simões S, Dias L, Kanudia A, Fortes P, Gargiulo M. Assessing the costeffectiveness of electric vehicles in European countries using integrated modeling. Energy Policy. 2015;80:165-76.

[10] Mohd TAT, Hassan MK, Aziz WMKA. Mathematical modeling and simulation of an electric vehicle. Journal of Mechanical Engineering and Sciences. 2015;8:1312-21.

[11] Zulkifli SA, Mohd S, Saad N, Aziz ARA. Operation and control of split-parallel, through-the-road hybrid electric vehicle with in-wheel motors. International Journal of Automotive and Mechanical Engineering. 2015;11:2793-808.

[12] Salisa AR, Walker PD, Zhang N, Zhu JG. Comparative cost-based analysis of a novel plug-in hybrid electric vehicle with conventional and hybrid electric vehicles. International Journal of Automotive and Mechanical Engineering. 2015;11:2262-71.

[13] Omar SMHS, Arshad NM, Yassin IM, Fakharuzi MHAM, Ward TA. Design and optimization of powertrain system for prototype fuel cell electric vehicle. Journal of Mechanical Engineering and Sciences. 2015;8:1401-13. 
[14] Wahono B, Santoso WB, Nur A. Analysis of range extender electric vehicle performance using vehicle simulator. Energy Procedia. 2015;68:409-18.

[15] Wahono B, Nur A, Santoso WB, Praptijanto A. A comparison study of rangeextended engines for electric vehicle based on vehicle simulator. Journal of Mechanical Engineering and Sciences. 2016;10:1803-16.

[16] Chen B-C, Wu Y-Y, Tsai H-C. Design and analysis of power management strategy for range extended electric vehicle using dynamic programming. Applied Energy. 2014;113:1764-74.

[17] Ribau J, Silva C, Brito FP, Martins J. Analysis of four-stroke, Wankel, and microturbine based range extenders for electric vehicles. Energy Conversion and Management. 2012;58:120-33.

[18] Hamut HS, Dincer I, Naterer GF. Exergy analysis of a TMS (thermal management system) for range-extended EVs (electric vehicles). Energy. 2012;46:117-25.

[19] Chen TD, Kockelman KM, Khan M. The electric vehicle charging station location problem: a parking-based assignment method for Seattle. Transportation Research Board 92nd Annual Meeting; 2013. p. 13-1254.

[20] Lieven T, Mühlmeier S, Henkel S, Waller JF. Who will buy electric cars? An empirical study in Germany. Transportation Research Part D: Transport and Environment. 2011;16:236-43.

[21] Aharon I, Kuperman A. Topological overview of powertrains for battery-powered vehicles with range extenders. IEEE transactions on Power Electronics. 2011;26:868-76.

[22] Jensen H, Schaltz E, Koustrup PS, Andreasen SJ, Kær SK. Evaluation of fuel-cell range extender impact on hybrid electrical vehicle performance. IEEE Transactions on Vehicular Technology. 2013;62:50-60.

[23] Yu J, Zhang Y, Liu N, Wang B. Modeling and control strategy simulation of extended-range electric vehicle. Transportation, Mechanical, and Electrical Engineering (TMEE), 2011 International Conference on: IEEE; 2011. p. 829-32.

[24] Wirasingha SG, Emadi A. Classification and review of control strategies for plugin hybrid electric vehicles. Vehicular Technology, IEEE Transactions on. 2011;60:111-22.

[25] Tie SF, Tan CW. A review of energy sources and energy management system in electric vehicles. Renewable and Sustainable Energy Reviews. 2013;20:82-102.

[26] Moura SJ, Fathy HK, Callaway DS, Stein JL. A stochastic optimal control approach for power management in plug-in hybrid electric vehicles. Control Systems Technology, IEEE Transactions on. 2011;19:545-55.

[27] Serrao L, Onori S, Rizzoni G. A comparative analysis of energy management strategies for hybrid electric vehicles. Journal of Dynamic Systems, Measurement, and Control. 2011;133:031012.

[28] Stockar S, Marano V, Canova M, Rizzoni G, Guzzella L. Energy-optimal control of plug-in hybrid electric vehicles for real-world driving cycles. Vehicular Technology, IEEE Transactions on. 2011;60:2949-62.

[29] Kim N, Cha S, Peng H. Optimal control of hybrid electric vehicles based on Pontryagin's minimum principle. Control Systems Technology, IEEE Transactions on. 2011;19:1279-87.

[30] Li SG, Sharkh SM, Walsh FC, Zhang C-N. Energy and battery management of a plug-in series hybrid electric vehicle using fuzzy logic. Vehicular Technology, IEEE Transactions on. 2011;60:3571-85.

[31] Powell MJD. Radial basis functions for multivariable interpolation: a review. Algorithms for approximation: Clarendon Press; 1987. p. 143-67. 
[32] Eberhart RC, Kennedy J. A new optimizer using particle swarm theory. Proceedings of the sixth international symposium on micro machine and human science: New York, NY; 1995. p. 39-43.

[33] Kennedy J. Particle swarm optimization. Encyclopedia of machine learning: Springer; 2011. p. 760-6.

[34] GKN. GKN Electric Motor And Generator Technology. 2016.

[35] Winston TS. WB-LYP200AHA. 2015.

[36] HPEVS. AC-20 Torque \& Horsepower, High Performance Electric Vehicle Systems. HPEVS; 2014. 